\title{
Pablo Macera: El oráculo que yo conocí
}

Conocí y estuve vinculado al Dr. Pablo Macera desde que era estudiante de arqueología, y continúe trabajando con el como investigador en el Seminario de Historia Rural Andina del Colegio Real por un periodo largo, donde realizamos muchos trabajos importantes como el proyecto de Pacopampa, que se gestó por su iniciativa, y finalmente el proyecto de la Amazonia, al que me dedico hasta el presente.

Esto me permitió conocerlo de forma integral, como historiador, político, crítico de arte y amigo, y fue así que lo reconocí como un verdadero oráculo, nombre o apodo con el que fue conocido en los círculos académicos o políticos. Su capacidad de visionario era tan famosa, que hacer una visita al seminario del Colegio Real era un parada obligada, era como entrar al santuario de Pachacamac, allí llegaban los investigadores, políticos y artistas que gustaban de conocer su opinión. Vienen a mi mente figuras como Alberto Flores Galindo, Nelson Manrique, Waldemar Espinoza, Lorenzo Huertas, Rex Gonzales, Alberto Flores Ochoa, Carlos Williams, John Murra, Ruth Shady, Rosa Fung, Ramiro Matos, Emilo Choy y muchos otros personajes famosos.

En cuanto a nuestra amistad y trabajo como investigador, aún recuerdo sus palabras cuando publique mi libro. Me dijo que yo también habia hecho mi propia historia prehispánica del Perú en el primer tomo del Compendio Histórico del Perú, publicado por la editorial Milla Batres en 1993. Según sus palabras textuales: «cada generación tiene el derecho de escribir su propia historia», por eso cada vez los arqueólogos están repensando la arqueología, eso implica también reconocer que hay varias historias sobre el Perú Prehispánico.

Eso es algo que yo aprendí de Macera, no solo por este dicho, sino por toda la trayectoria que dejó a la sociedad este ilustre maestro.

Su destacado interés por la historia prehispánica, lo llevó a hacer una síntesis apretada pero contundente titulada: Visión Histórica del Perú, donde recalca que quizás es conveniente hablar de las diferentes historias ocurridas en este territorio, que desde hace pocos años se ha comenzado a llamar Perú. Fue un buen inicio, el interactuar con los arqueólogos y aprender también de ellos. Lo que siempre admiré fue su método de estudio, al hacer su registro de la cultura material arqueológica, el cual, como buen historiador lo trasladó a los hechos y acciones presentes o lo que podría llamarse cultura viva, construyendo una historia más verídica, nada inventada, que no se parezca a un cuento, es decir, una nueva historia desde el punto de vista de los actores vivos, y que en todas las historias no fueron tomados en cuenta, separándose así más de la fuente etnohistórica, construyendo otra historia distinta a la de María Rostworowski, Waldemar Espinoza y otros historiadores clásicos de su generación. Ese acercamiento temprano a la arqueología a fines de la década de los años 70, lo llevó a apostar por el desarrollo de la arqueología, que en aquellos tiempos estaba monopolizada por solo tres o más arqueólogos que

(C) Los autores. Este artículo es publicado por ISHRA, Revista del Instituto Seminario de Historia Rural Andina de la Facultad de Ciencias Sociales de la Universidad Nacional Mayor de San Marcos. Este es un artículo de acceso abierto, distribuido bajo los términos de la licencia Creative Commons Atribución 4.0 Internacional (CC BY 4.0) [https://creativecommons.org/licenses/by/4.0/deed.es] que permite el uso, distribución y reproducción en cualquier medio, siempre que la obra original sea debidamente citada de su fuente original. 
se peleaban por la hegemonía, es por ello que Macera decía que «los arqueólogos eran caníbales» El trató de cambiar esa situación, protegiendo y alentando a los arqueólogos jóvenes, esa fue su intención al impulsar el Proyecto Arqueológico Pacopampa (figura 1), donde dio oportunidad a todos los estudiantes y recién egresados de la Universidad San Marcos. Impulsó otra forma de hacer la arqueología, no solo vinculada a la investigación sino también a la protección y conservación del monumento arqueológico, y desarrollando con la comunidad el respeto por el legado de sus ancestros y con el propósito de convertirlo en un recurso económico, vinculado a la enseñanza local y turismo, regional, nacional e internacional. Este es un legado que el Ministerio de Cultura no supo capitalizar en su política de investigación, enseñanza, conservación, defensa y puesta en valor de los sitios arqueológicos del Perú.

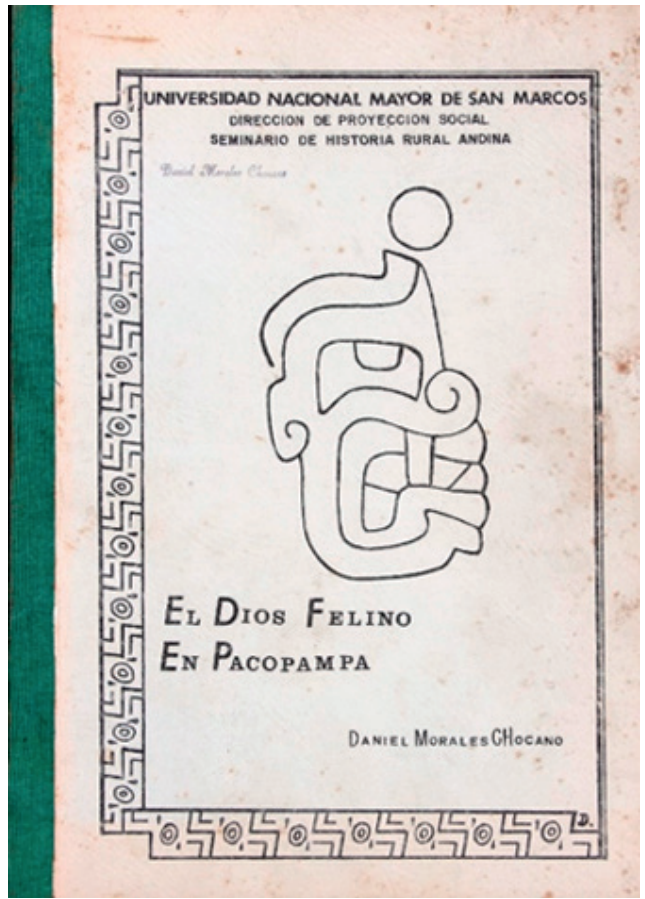

Figura 1. Carátula del libro: El Dios Felino en Pacopampa. Fotografía: Omar Esquivel.

Su amistad y conversación con los arqueólogos lo llevo a confiar más en el registro de la cultura material viva (figura 2), de los sectores más olvidados, para elaborar con ellos una nueva historia, diferente a la oficial, en verdad, historias rurales como producto de la diversidad cultural de nuestro país, obligándonos a dar cuenta de que el Perú tiene varias historias, es multinacional, en donde la historia oficial es solamente la continuación del relato de los conquistadores españoles; él nos dio a entender que el Perú hasta hoy no ha podido reconstruir su propia historia, la cual es multicultural, plurilinguista y tan diversa como su geografía.

Dentro de esta forma de hacer historia, puso en agenda estos últimos años, a los nativos amazónicos, quienes en base a su arte, mitos y leyendas, construyeran la historia olvidada del otro personaje olvidado que vive también en el país.

La vida de Macera no se resume a la frase «el Perú es un burdel», hay que entender esta frase en el más amplio sentido de la palabra, es una especie de iconografía para comprender el ámbito político, económico e ideológico del Perú. Es que Macera fue un historiador de muchas aristas, no solo a nivel intelectual, sino también a nivel político, económico y personal. Un ejemplo es 
que gracias a su carácter enérgico y apabullante pudo conseguir la creación del Seminario de Historia Rural Andina, como un centro de investigación permanente dentro de la Universidad San Marcos, del cual fue director, y desde ese lugar apoyó y gestionó a la investigación en historia, arte y arqueología, y en donde todos los días se daban tertulias y entrevistas de forma constante, creando un entorno muy grande de intelectuales y no intelectuales que lo respetaban, por esta razón el Seminario de Historia Rural Andina, con más de 50 años de vida, tiene una innumerable producción académica, que hoy los jóvenes y nuevas autoridades de la universidad no conocen, e ignoran el valor que representa; como resultado de esto, el Seminario ha sido desarticulado y hoy se encuentra a punto de la extinción.

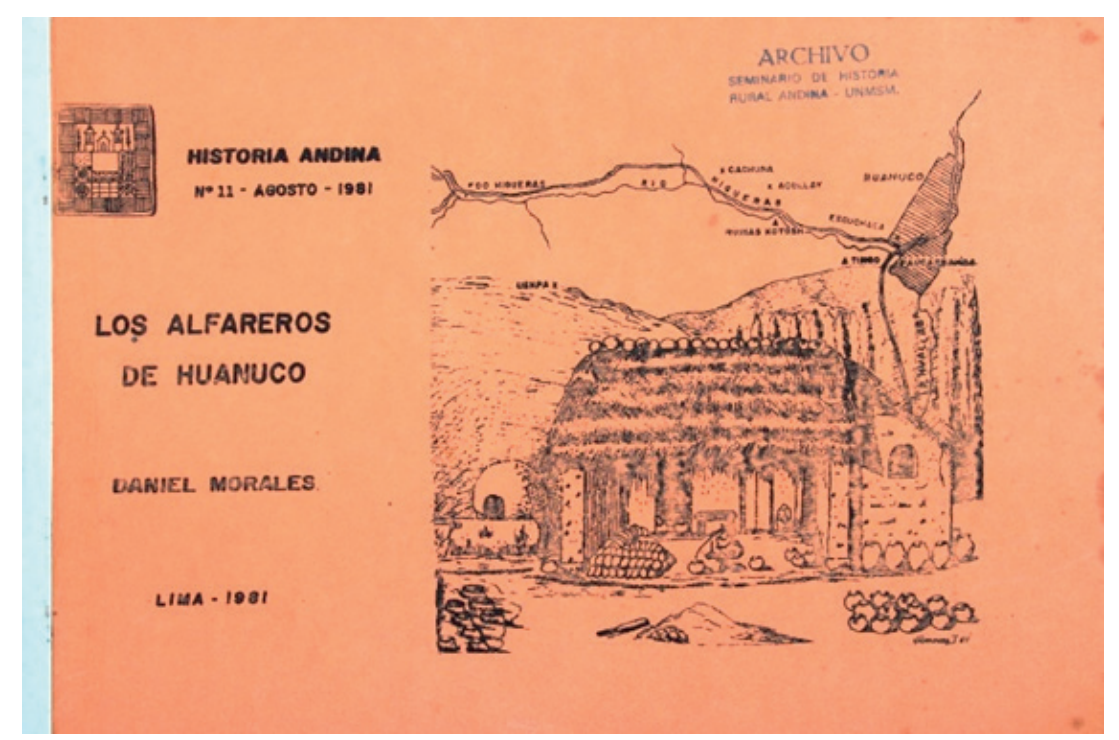

Figura 2. Carátula del libro: Los alfareros de Huánuco. Fotografía: Omar Esquivel.

Otro aspecto de su vida personal, es que su economía siempre fue angustiosa, el ingreso de profesor universitario siempre es mísero. Recuerdo que se asoció con el arqueólogo Víctor Chang, para criar abejas y sembrar árboles frutales en Sayán, por supuesto que el resultado fue pésimo. Bajo esta situación yo entiendo y justifico la participación de Pablo Macera en el Fujimorismo, lo que no es justo y grato, es que casi todos sus amigos y admiradores le dieron la espalda y lo arrinconaron a retraerse totalmente hasta sus últimos días, a pesar de que él hizo un juego limpio, transparente y sin trampas, mientras que otros docentes universitarios con sueldos míseros se convirtieron en ejemplos de la corrupción, lucrando con el presupuesto y recursos propios de la universidad, dejándola en el atraso, y hoy ya es difícil poner a la universidad a la altura de otras similares de gran desarrollo y tecnología; por eso los alumnos siempre protestan y nunca se les hace caso.

Creo que Pablo Macera luchó siempre porque la universidad de San Marcos alcanzara niveles académicos importantes, sin olvidarse de los grupos marginados que nunca figuraron en la agenda social de los investigadores; él les dio el espacio para hacerlo y los empoderó para que lograran un lugar dentro de la sociedad, prueba de ello es la presencia de los artistas amazónicos, Shipibos, Huitotos, Ashaninkas y andinos también, fue un gran visionario en su propio país. Macera los descubrió y logró darles valor agregado a su quehacer, y actualmente representan al país en muchos eventos internacionales como Art Madrid, aunque siempre están relegados por aquellos que los utilizan para exhibirlos como figuras exóticas. 
Asimismo, él fue el gran descubridor del gran centro ceremonial de Pacopampa al mismo estilo de Hiram Bingham con Machu Picchu. Aún queda mucho por revalorar de su legado a la arqueología, historia, arte, etnografía y a su alma mater la universidad de San Marcos a la que le dedicó gran parte de su vida.

\section{Daniel Morales Chocano}

dmoralesc1@unmsm.edu.pe

Universidad Nacional Mayor de San Marcos

Publicado online: 27/12/2021 